\title{
PERANCANGAN APLIKASI SISTEM INFORMASI MANAJEMEN BARANG PADA PLANET COMPUTER BERBASIS JAVA NETBEANS
}

\author{
Ivan Fahrizal ${ }^{1}$, Juliana ${ }^{2}$, Heri Satria Setiawan ${ }^{3}$ \\ Program Studi Teknik Informatika, Fakultas Teknik dan Ilmu Komputer, \\ Universitas Indraprasta PGRI \\ Jalan Raya Tengah No 80, Kelurahan Gedong, Pasar Rebo, Jakarta Timur \\ ivan.fahrizal27@gmail.com ${ }^{1}$, julianajuli220220@gmail.com ${ }^{2}$, herisatria20@gmail.com ${ }^{3}$
}

\begin{abstract}
Abstrak
Perkembangan didunia teknologi sangat berkembang dengan pesat. Segala macam tekonologi dibuat untuk membuat kemudahan kepada pengguna teknologi. Perkembangan teknologi pada era modern sekarang ini pesat seperti contohnya seperti perangkat komputer atau laptop biasanya digunakan untuk kebutuhan seperti membuat laporan, program, berkomunikasi, membuat animasi, editing dan masih banyak kegiatan yang bisa dilakukan oleh perangat tersebut. Begitu pula juga dengan usaha pada Planet Computer merupakan badan usaha milik pribadi yang bergerak dibidang penjualan, dan servis komputer atau laptop maupun printer dimana saat ini sistemnya masih belum terkomputerisasi dengan baik. Tujuan penelitian adalah untuk membuat sebuah sistem pendataan pemasukan barang, penjualan dan kebutuhan stok barang pada Planet Computer. Membuat aplikasi manajemen barang yang dapat mempermudah usaha dalam kegiatan pemasukan barang dan penjualan. Mempermudah karyawan dalam proses penyimpanan data stok barang, data barang masuk, data penjualan data servis dan pembuatan laporan yang sudah terkomputerisasi agar tidak terjadi kesalahan dalam pembuatan laporan.
\end{abstract}

Kata Kunci : Management Barang, Servis, Java.

\begin{abstract}
The development in the world of technology is developing rapidly. All kinds of technology are made to make it easy for technology users. The development of technology in today's modern era is rapid, for example, such as a computer or laptop device, usually used for needs such as making reports, programs, communicating, making animations, editing and there are still many activities that can be done by these players. Likewise, the business at Planet Computer is a privately owned business entity engaged in the sale, and servicing of computers or laptops and printers where the current system is still not computerized properly. The purpose of this research is to create a data collection system for the importation of goods, sales and stock requirements on Planet Computer. Creating an item management application that can simplify business in goods import and sales activities. Facilitate employees in the process of storing inventory data, incoming goods data, sales data, service data and making reports that have been computerized to avoid mistakes in making reports.
\end{abstract}

Keyword :Stuff Management, Services, Java

\section{PENDAHULUAN}

Perkembangan zaman pada saat ini membuat komputer dan laptop menjadi sebuah barang yang sangat dibutuhkan untuk melaksanakan setiap aktivitas di semua bidang. Planet Computer adalah sebuah usaha yang bergerak dalam bidang pelayanan jasa servis dan penjualanan barang komputer /laptop. Dalam kegiatannya, Planet Computer menerima dan memenuhi permintaan pelayanan servis komputer, laptop dan printer berbagai jenis merek dari pelanggan. Pada Planet Computer sebelum peneliti membuat aplikasi, pendataan laporan masih menggunakan cara manual diantaranya : sistem pada Planet Computer masih dikerjakan secara manual dari membuat laporan hingga mencari data barang oleh karena itu peneliti mengusulkan membuat Perancangan Sistem Informasi Manajemen Barang pada Planet Computer Berbasis Java Netbeans. Peneliti disini menggunakan Aplikasi Java Netbeans, (Supardi 2010) menyatakan bahwa Java merupakan pemrograman yang dikembangkan dari Bahasa pemrograman $\mathrm{C}++$, sehingga Bahasa pemrograman ini seperti Bahasa C++. Menurut (Hastuti and Yusril 2018) Netbeans adalah sebuah Integrated Development Environtment atau yang disingkat IDE yang sangat Tangguh untuk membuat aplikasi 
berbasis Java. Netbeans awalnya merupakan proyek open source dari Sun Microsystem namun kemudian berpindah tangan ke Oracle. Netbeans sangat nyaman digunakan untuk membuat aplikasi desktop menggunakan Swing atau JavaFx. Menurut (Juhara 2016) Sebuah aplikasi berada dalam proses yang berdiri sendiri, di mana tiap proses terdiri dari sebuah thread atau lebih. Ketika sistem operasi memuat sebuah aplikasi, sebuah proses akan tercipta dan membaca parameter pada command line. Lalu, melalui titik masuk tunggal, sistem operasi akan memuat kode program dan mulai mengeksekusi kode-kode tersebut. sedangkan menurut (Suartama 2015) Mendefinisikan aplikasi sebagai perangkat lunak atau software jadi siap digunakan. Software ini merupakan program yang khusus melakukan suatu perkerjaan tertentu Software atau perangkat lunak, merupakan sebuah program. Peneliti disini juga menggunakan database MySQL untuk menyimpan data stok barang, barang masuk, penjualan, dan servis, menurut (Yanto 2016) Database adalah sekumpulan dari file-file yang dilengkapi dengan atribut dan record yang saling berinteraksi untuk mencapai tujuan menghasilkan informasi yang dibutuhkan oleh pihak pengguna. Menurut (Kustiyaningsih, Yeni. 2011) MySQL merupakan database server open source yang cukup popular keberadaannya. Dengan berbagai keunggulan dimiliki, database ini banyak digunakan oleh praktisi untuk membangun suatu proyek. Adanya fasilitas API (Application Programming Interface) yang dimiliki oleh MySQL, memungkinkan bermacam-macam aplikasi komputer yang ditulis dengan berbagai bahasa pemrograman dapat mengakses database MySQL. Disini peneliti menggunakan Manajemen untuk mengatur barang-barang di Planet Computer, menurut (Danupranata 2013) Manajemen adalah sebuah kata bebas nilai, bergantung pada fungsi dan kegunaan yang akan diharapkan. Manajemen berarti seni dan ilmu pengelolaan yang berisi atau berfungsi untuk melakukan perencanaan, pengorganisasian, pengarahan, dan pengawasan. Menurut (Rusdiana 2014) Manajemen adalah proses bekerja untuk mencapai tujuan yang telah ditetapkan sebelumnya secara efektif dan efisien dengan menggunakan orang-orang melalui perencanaan (planning), pengaturan (organizing), kepemimpinan (leading), dan pengendalian (controling) dengan memanfaatkan sumber daya yang tersedia.

\section{PENELITIAN RELEVAN}

Terdapat tiga penelitian relevan yang peneliti gunakan dalam penelitian ini, yaitu pertama penelitian yang dilakukan oleh Suprayitno dan Uli Indah Wardati dalam jurnal yang berjudul Pembangunan Sistem Stok Barang Penjualan Pada Toko Sero Elektronik publikasi Universitas Negeri Surakarta volume 9 No. 3, ISSN 1979-9330 tahun 2012 dari hasil penelitian yang dilakukan ini adalah telah berhasil dibangunnya sistem stok barang serta penjualan di toko sero elektronik, kedua penelitian yang dilakukan oleh Saprudin dan Ade Hermawan dalam jurnal yang berjudul Perancangan Sistem Inventory Menggunakan Metode Waterfall Pada PT. Lestari Busana Anggun Mahkota publikasi Universitas Pamulang volume 4 No. 2, ISSN 2549-4805 tahun 2019 dari hasil penelitian yang dilakukan telah berhasil mengefisiensikan kinerja karyawan pada PT. Lestari Anggun Mahkota dan menkomputerisasikan dalam mengelola pendataan, dan ketiga penelitian yang dilakukan oleh Muhamad Tabrani dan Eni Pudjiarti dalam jurnal yang berjudul Penerapan Metode Waterfall Pada Sistem Informasi Inventori PT. Pangan Sehat Sejahtera Publikasi Universitas STMIK Nusa Mandiri Jakarta volume 1 No.2 ISSN 2615-3545 tahun 2017 dari hasil penelitian yang dilakukan mengkomputerisasikan pengelolahan data serta pembuatan laporan data asset yang akurat.

\section{METODE PENELITIAN Studi Pustaka}

Pengumpulan data dan informasi dilakukan dengan mempelajari buku-buku yang berhubungan dengan masalah yang sedang peneliti bahas. Informasi yang didapat berasal dari perpustakaan universitas, perpustakaan umum kota, dan perpustakaan nasional.

\section{Observasi}

Observasi merupakan suatu cara pengumpulan data dengan mengadakan pengamatan langsung terhadap suatu objek dalam suatu periode tertentu dan mengadakan pencatatan secara sistematis tentang hal-hal tertentu yang diamati. 


\section{Wawancara}

Wawancara merupakan suatu teknik pengumpulan data yang dilakukan dengan cara tanya jawab antara penanya dengan responden. Wawancara yang dilakukan dengan bertanya secara langsung atau menggunakan questioner yang telah peneliti buat sebelumnya. Questioner akan berisi pertanyaan seputar permasalah yang dihadapi dan solusi apa yang dibutuhkan oleh pemilik Planet Computer guna menunjang serta memberikan kemudahan dalam pekerjaan mereka.

\section{Langkah-Langkah Pengembangan Sistem}

Metode yang digunakan adalah Waterfall menurut teori (Sommerville 2011) tahapan utama dari waterfall model langsung mencerminkan aktifitas pengembangan dasar. Terdapat 5 tahapan pada waterfall model, yaitu :

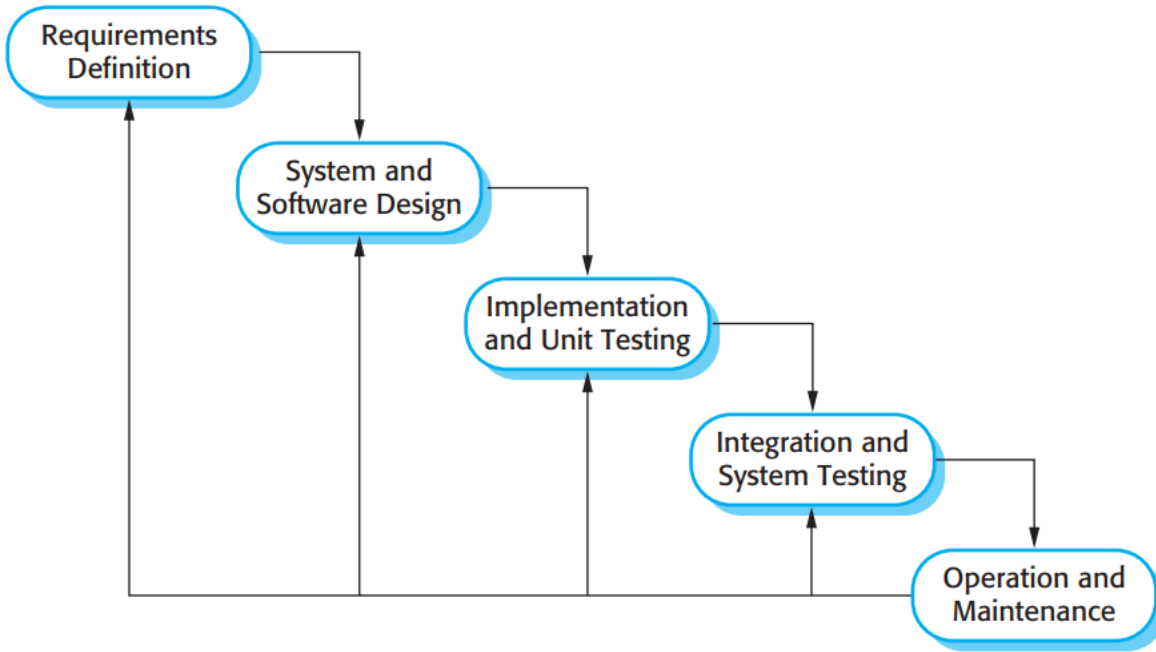

Gambar 1. Metode Pengembangan Sistem Waterfall

(Sumber : Sommerville, 2011)

\section{Requirements Definition}

Merupakan tahapan penetapan fitur, Analisa kendala dan tujuan sistem melalui konsultasi dengan pengguna sistem. Semua tahapan tersebut akan ditetapkan secara rinci dan berfungsi sebagai spesifikasi sistem.

\section{System and Software Design}

Merupakan tahapan pembentukan arsitektur sistem berdasarkan persyaratan yang telah ditetapkan pada tahap ini juga mengidentifikasi dan menggambarkan abstraksi dasar sistem perangkat lunak yang akan dibuat serta hubungan-hubungannya.

\section{Implementation and Unit Testing}

Merupakan tahapan hasil dari desain perangkat lunak untuk direalisasikan sebagai satu set program atau unit program. Setiap unit akan diuji apakah sudah memenuhi spesifikasinya.

\section{Intergration and System Testing}

Merupakan tahapan perintergrasian setiap unit program satu sama lain dan diuji sebagai satu sistem yang utuh untuk memastikan ssitem sudah memenuhi persyaratan yang ada. Setelah itu sistem akan dikirim pengguna sistem.

\section{Operration and Maintenance}

Merupakan tahapan perinstalasian dan penerapan sistem. Pada tahap ini juga dilakukan pengujian pada saat sistem dijalankan untuk menemukan dan memperbaiki error yang tidak ditemukan pada tahap pembuatan

\section{HASIL DAN PEMBAHASAN}

\section{Analisa Permasalahan}

Dari hasil penelitian yang dilakukan oleh peneliti dapat menganalisa sistem permasalahan yang ada pada sistem perancangan penjualan servis di planet computer yaitu:

1. Manajemen stok barang dan servis masih belum terkomputerisasi, sehingga dalam pembuatan tanda bukti penjualan servis masih manual. 
2. Pendataan barang dalam bentuk informasi belum terpenuhi dengan baik

3. Proses penjualan yang belum menggunakan sistem yang baik, sehingga menyebabkan lambatnya penghitungan pembelian barang sehingga belum efektif dan efesien.

\section{Alternatif Penyelesaian Masalah}

Berdasarkan masalah yang diteliti, peneliti memberikan alternatif yang bias menjadi penyelesaian masalah pada planet computer yaitu:

1. Membuat aplikasi manajemen barang yang dapat mempermudah usaha dalam kegiatan pemasukan barang dan penjualan.

2. Mempermudah karyawan dalam proses penyimpanan data stok barang, data barang masuk, data penjualan, dan data servis.

3. Dalam pembuatan laporan membuat sistem secara terkomputerisasi agar tidak terjadi kesalahan dalam pembuatan laporan

\section{Diagram Alur Data (DAD)}

Menurut (Subhan 2012), Diagram alur data merupakan model dari sistem untuk menggambarkan pembagian sistem ke modul yang lebih kecil. Salah satu keuntungan menggunakan diagram alur data ialah memudahkan pemakai atau user yang kurang menguasai bidang komputer untuk mengerti sistem yang akan digunakan. Berikut bentuk diagram alur data dari manajemen barang pada planet computer:

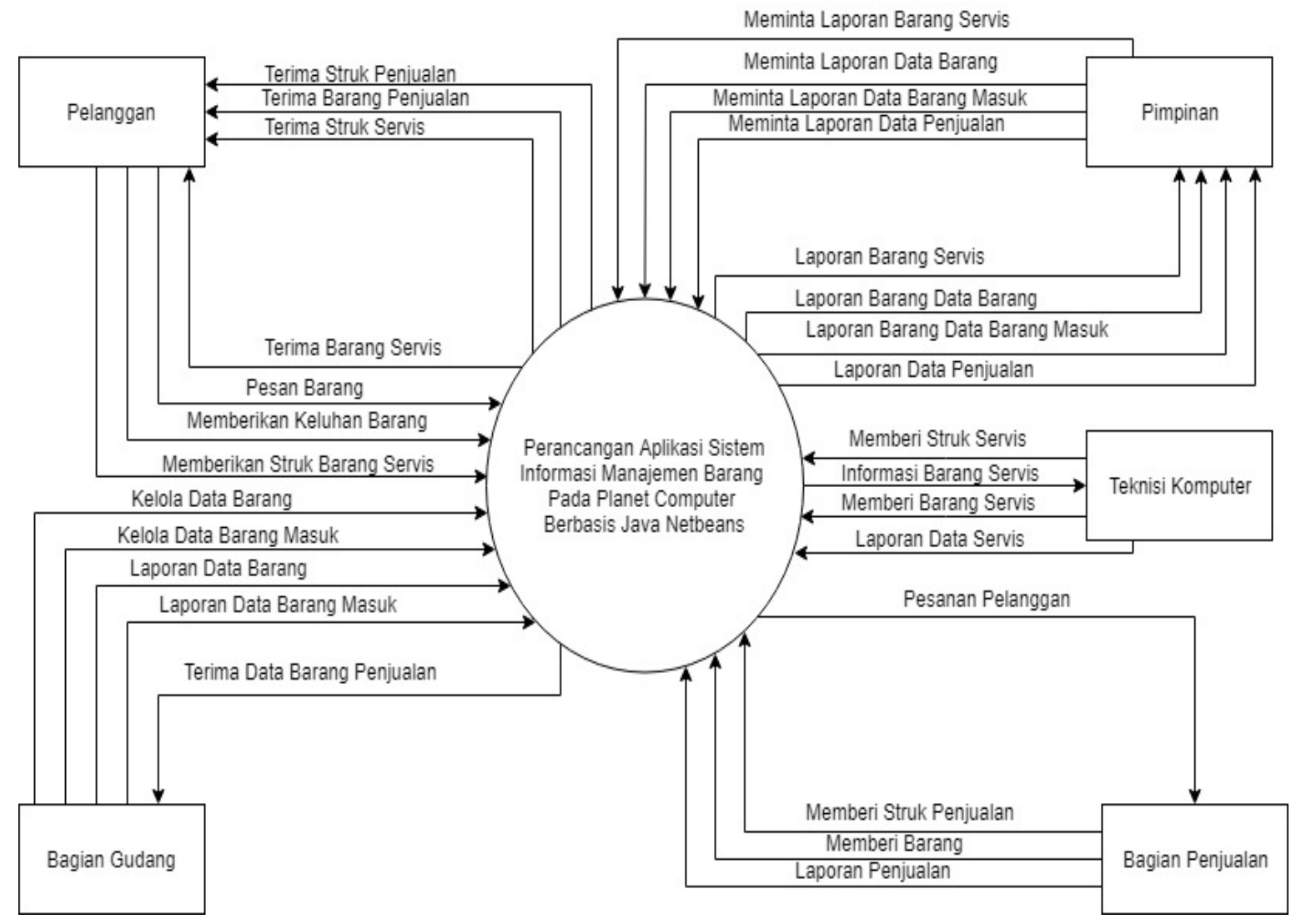

Gambar 2. Diagram Konteks Sistem yang Diusulkan 


\section{Tampilan Layar}

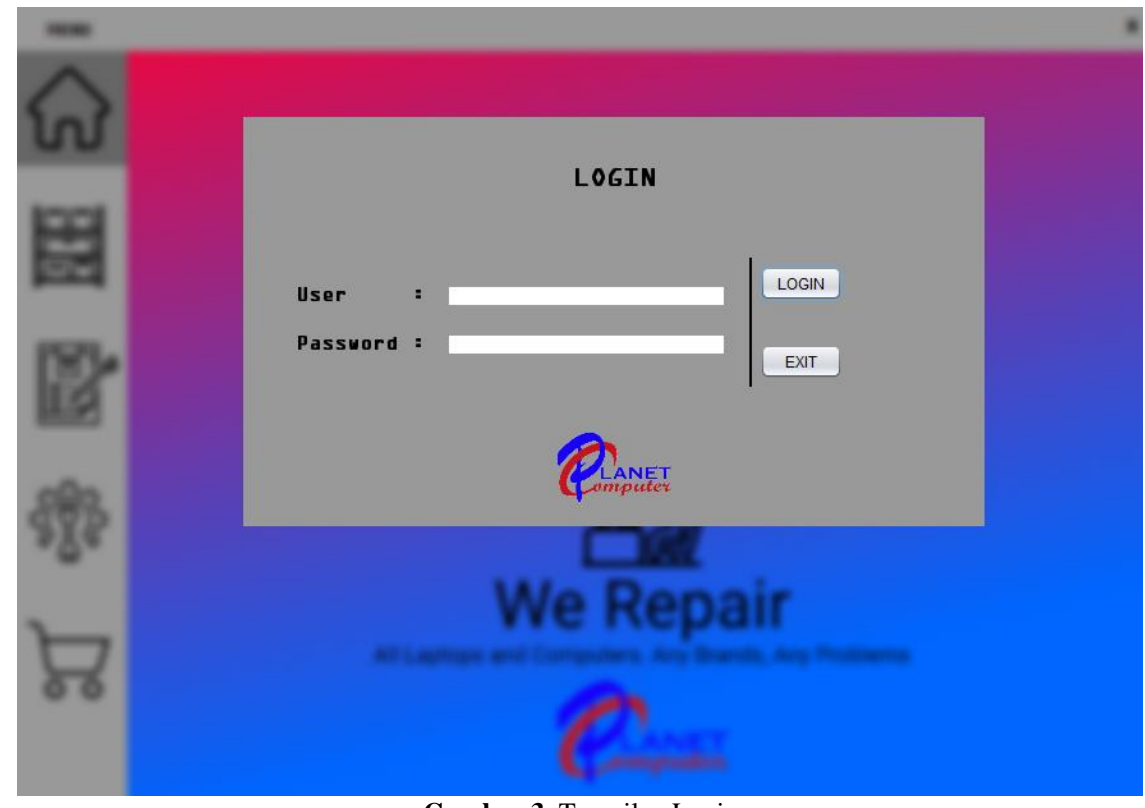

Gambar 3. Tampilan Login

Tampilan layar menu login ini muncul di awal pengoperasian program aplikasi penjualan dan servis untuk diisi oleh pegawai toko. Masukkan user dan password yang sesuai supaya bisa mengoperasikan aplikasi penjualan dan servis, kemudian klik login. Jika user dan password sesuai setelah tekan tombol login maka akan muncul tampilan menu utama, sedangkan tombol exit digunakan untuk menutup aplikasi.

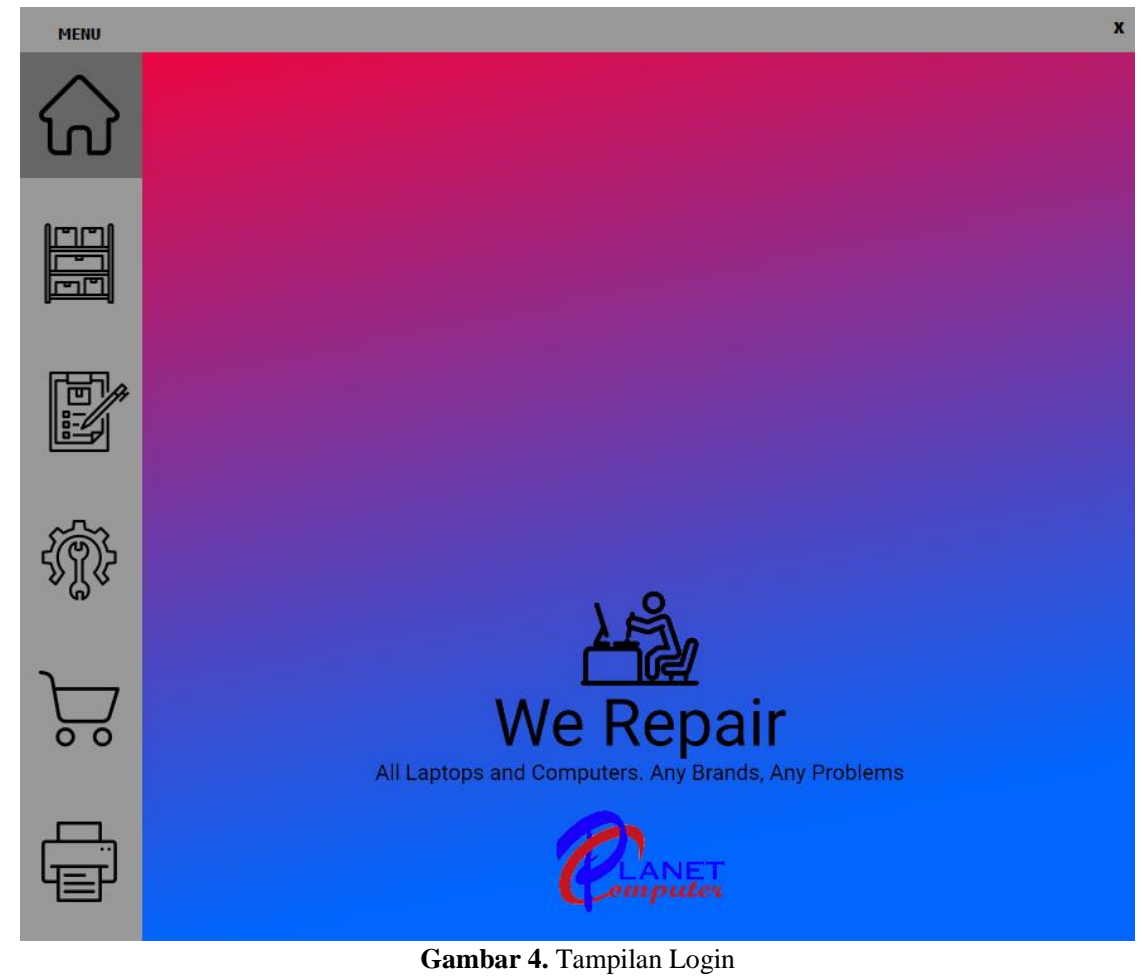

Menu utama ini terdapat beberapa tombol yang akan menampilkan form diantaranya adalah :

1) Stok Barang, akan menampilkan form stok barang yang berfungsi untuk membuat pendataan barang.

2) Barang Masuk, akan menampilkan form barang masuk yang berfungsi untuk membuat pendataan ulang barang yang ingin di stok ulang.

3) Servis, akan menampilkan form servis yang berfungsi untuk mendata pemiliki barang dan barang servisnya. 
4) Penjualan, akan menampilkan form penjualan yang berfungsi untuk mendata barang yang dijual didalam stok barang.

5) Laporan, akan menampilkan form laporan yang berfungsi untuk mencetak laporan bulanan yang di lakukan di form stok barang, barang masuk, servis, dan penjualan.

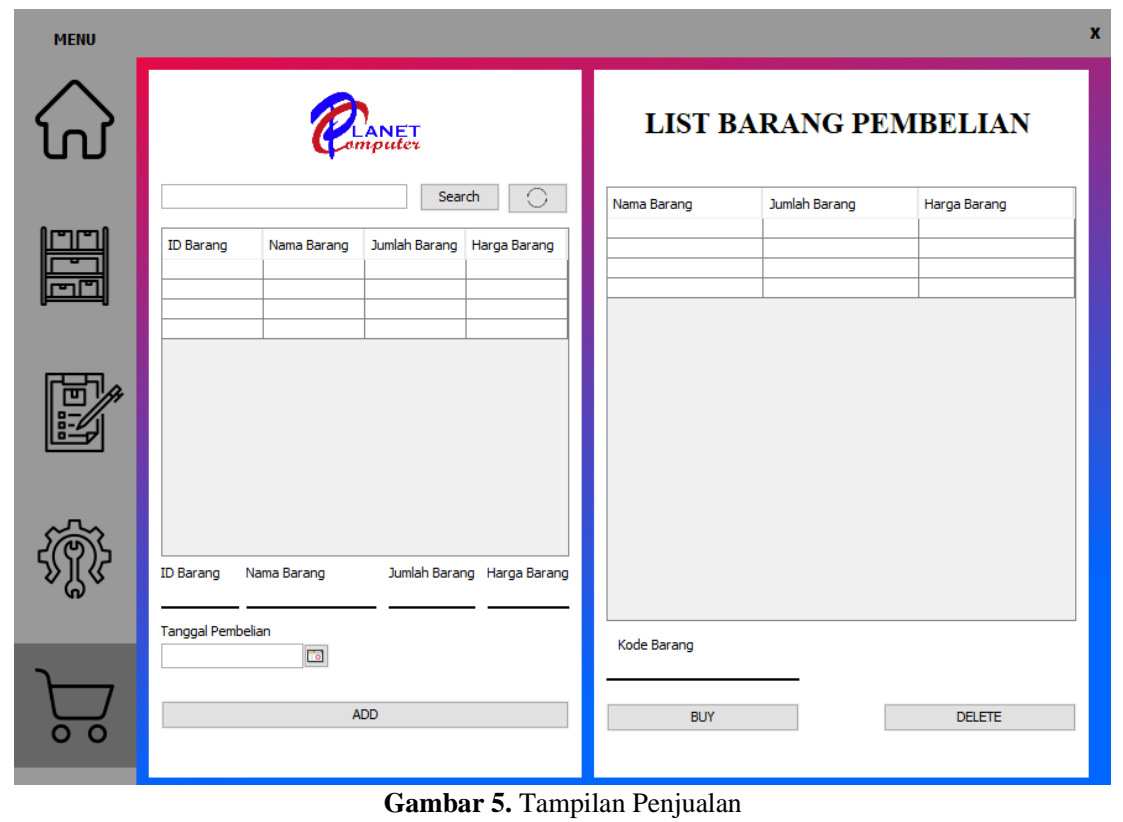

Rancangan form penjualan ini dibuat untuk mendata barang yang dijual. Untuk dapat melakukan penjualan data hanya perlu memasukkan data pada kolom yang tersedia, kemudian klik tombol add. Apabila data ingin di hapus klik data pada tabel lalu klik tombol delete maka data akan terhapus. Jika sudah melakukan add untuk barang yang sudah di pilih, maka bisa langsung mengklik data pada tabel lalu klik tombol buy maka data akan membuat struk penjualan. Apabila ingin kembali ke menu utama bisa dilakukan dengan cara klik tombol home maka akan muncul tampilan menu utama.

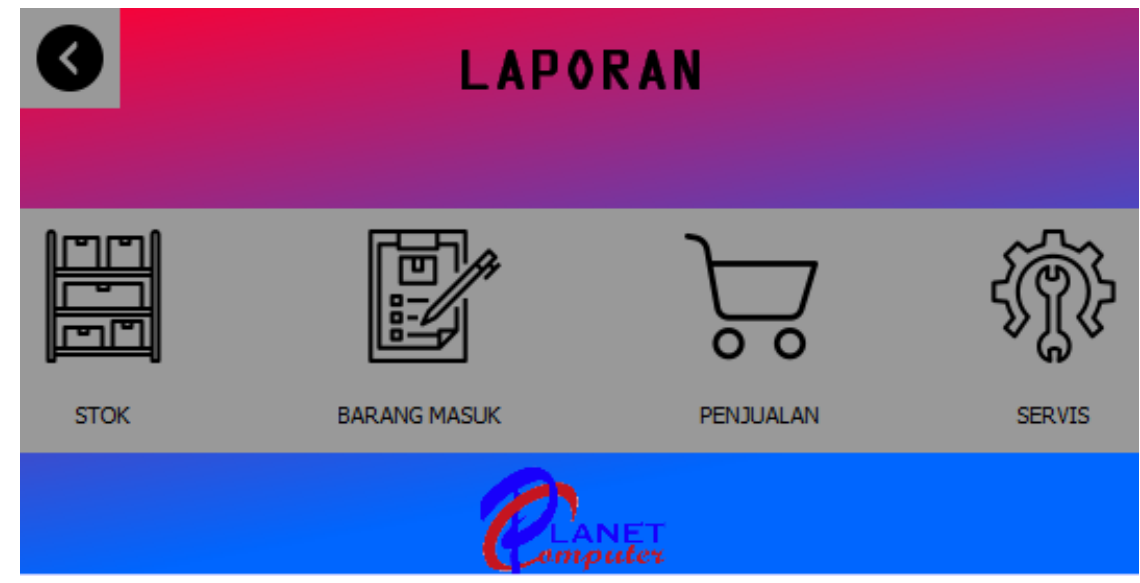

Gambar 6. Tampilan Penjualan

Tampilan form laporan ini dibuat untuk mencetak laporan bulanan yang di lakukan pada form stok barang, barang masuk, servis, dan penjualan. Untuk mencetak stok barang yang ada ditoko hanya perlu klik tombol stok, maka akan muncul list laporan stok barang apa saja yang ada didalam stok barang tersebut. Apabila mencetak barang masuk hanya perlu klik tombol barang masuk, maka akan muncul list laporan barang masuk apa saja yang ada didalam barang masuk tersebut. Apabila mencetak penjualan hanya perlu klik tombol penjualan, maka akan muncul list laporan penjualan apa saja yang telah di jual didalam laporan penjualan tersebut. Apabila mencetak servis hanya perlu 
klik tombol servis, maka akan muncul list laporan yang telah menggunakan jasa servis perbaikan komputer laptop.

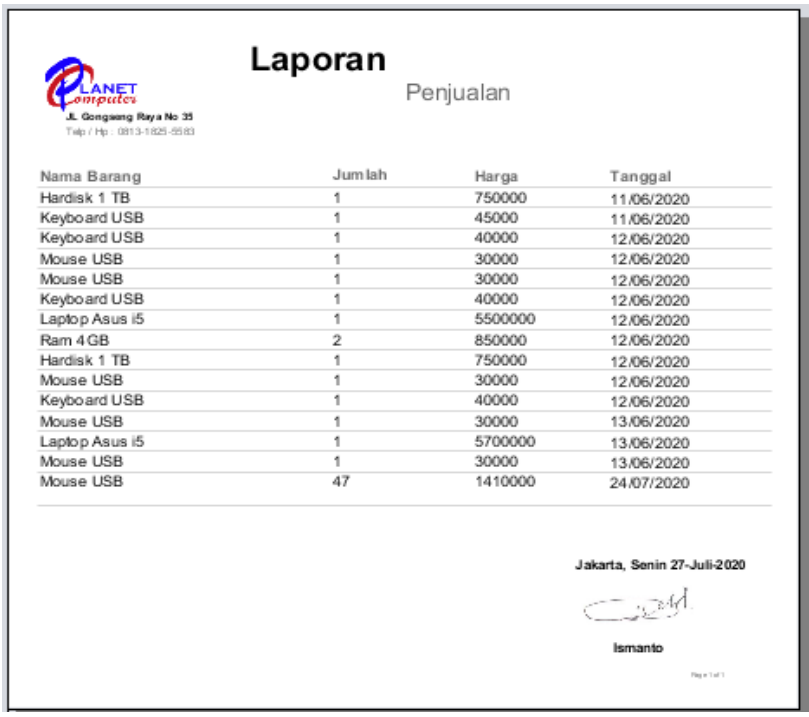

Gambar 7. Tampilan Laporan Penjualan

Tampilan laporan tabel dari penjualan ini, terdiri dari list nama barang, jumlah, harga dan tanggal barang yang di beli oleh pelanggan disetiap barang nya. Fungsi dari tampilan ini untuk mencetak laporan yang telah di input dari form penjualan.

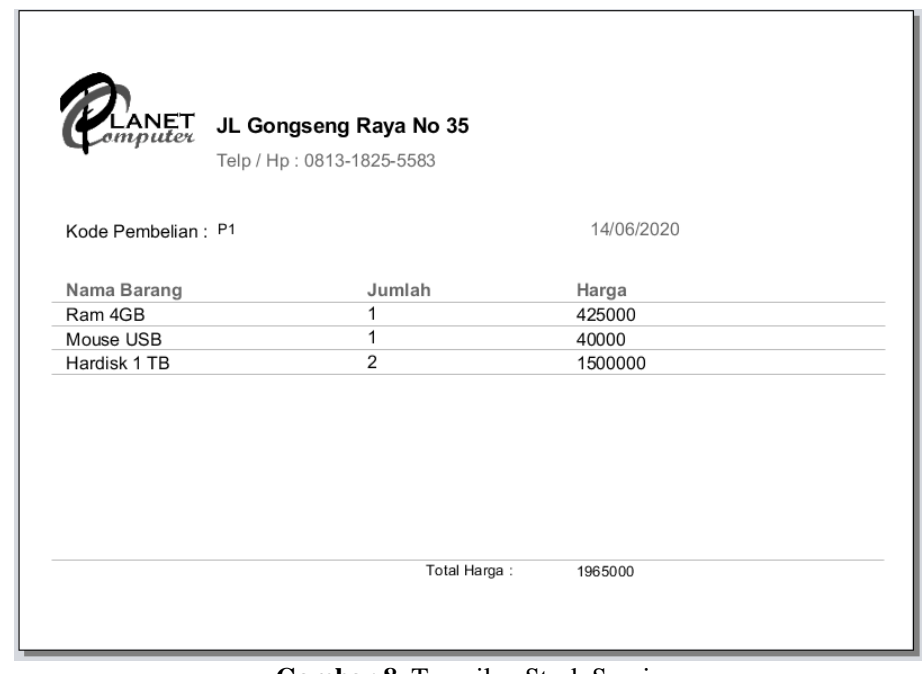

Gambar 8. Tampilan Struk Servis

Tampilan laporan struk pembelian ini, terdiri dari list kode barang, nama barang, jumlah, harga, total harga yang dibeli. Fungsi dari tampilan ini untuk mencetak laporan yang telah di input dari form penjualan.

\section{SIMPULAN}

Aplikasi yang peneliti buat memberikan kemudahan kepada pihak pemilik toko Planet Computer dalam melakukan kegiatan jual, beli, servis, dan dalam melakukan manajemen data produk komponen komputer atau laptop yang dipasarkan dan hadirnya aplikasi ini memberikan kemudahan untuk mengetahui apa saja produk komponen komputer yang ditawarkan secara real time. 


\section{DAFTAR PUSTAKA}

Danupranata, Gita. 2013. Buku Ajar Manajemen Perbankan Syariah. Jakarta: Salemba Empat.

Hastuti, Dwi, and Arief Yusril. 2018. Belajar Pemrograman Java Menggunakan Java FX Dan Database H2. Yogyakarta: Aswaja Pressindo.

Juhara, P Zamrony. 2016. Panduan Lengkap Pemrograman Android. Yogyakarta: CV. Budi Utama.

Kustiyaningsih, Yeni., R.A. Devie. 2011. Pemrograman Basis Data Berbasis Web Menggunakan PHP \& MySQL. Yogyakarta: Graha Ilmu.

Rusdiana, A. 2014. Manajemen Operasi. Bandung: CV Pustaka Setia.

Sommerville, Ian. 2011. Software Engineering. United States: Pearson Education.

Suartama, Kadek. 2015. E-Learning Berbasis Moodle. Tanggerang: Graha.

Subhan, Mohamad. 2012. Analisa Perancangan Sistem. Jakarta: Lentera Ilmu Cendikia.

Supardi, Yuniar. 2010. Semua Bisa Menjadi Programmer Java Basic Programming. Jakarta: Elex Media Komputindo.

Yanto, Robi. 2016. Manajemen Basis Data Menggunakan MySQL. Yogyakarta: Deepublish. 